\title{
Research on the Effects of Hydropneumatic Parameters on Tracked Vehicle Ride Safety Based on Cosimulation
}

\author{
Shousong Han, Zhiqiang Chao, and Xiangbo Liu \\ Department of Mechanical Engineering, Academy of Armored Forces Engineering, Beijing 100072, China \\ Correspondence should be addressed to Shousong Han; hssbeijing@163.com
}

Received 14 February 2017; Revised 24 May 2017; Accepted 15 June 2017; Published 20 September 2017

Academic Editor: Matteo Aureli

Copyright (C) 2017 Shousong Han et al. This is an open access article distributed under the Creative Commons Attribution License, which permits unrestricted use, distribution, and reproduction in any medium, provided the original work is properly cited.

\begin{abstract}
Ride safety of a tracked vehicle is the key focus of this research. The factors that affect the ride safety of a vehicle are analyzed and evaluation parameters with their criteria are proposed. A multibody cosimulation approach is used to investigate the effects of hydropneumatic parameters on the ride safety and aid with design optimization and tuning of the suspension system. Based on the cosimulation environment, the vehicle multibody dynamics (MBD) model and the road model are developed using RecurDyn, which is linked to the hydropneumatic suspension model developed in Lab AMESim. Test verification of a single suspension unit is accomplished and the suspension parameters are implemented within the hydropneumatic model. Virtual tests on a $G$ class road at different speeds are conducted. Effects of the accumulator charge pressure, damping diameter, and the track tensioning pressure on the ride safety are analyzed and quantified. This research shows that low accumulator charge pressure, improper damping diameter, and insufficient track tensioning pressure will deteriorate the ride safety. The results provide useful references for the optimal design and control of the parameters of a hydropneumatic suspension.
\end{abstract}

\section{Introduction}

Hydropneumatics is a technology typically used in vehicle suspensions. A hydropneumatic suspension has good properties such as nonlinear stiffness and damping, high power density, convenient tuning, and vertical position locking. Thus, it is widely used in tracked vehicles and improves ride comfort. In practical applications, common failures are the track separating from the road wheel or the sprocket. These failures may result in the vehicle losing control and bring very serious implications in terms of vehicle ride safety.

Previous studies have done some dynamic simulation analysis on the issue of track separating from the road wheel. It has been shown that improper tuning of the suspension parameters is the main reason for such failures $[1,2]$. For a hydropneumatic suspension system, the primary parameters are the accumulator charge pressure and the damping. If these parameters are not tuned properly, or if they vary because of external gas leakage and internal oil leakage, then ride safety can be severely compromised. Currently, most research investigations focus on vehicle ride comfort, with little attention given to ride safety. Some dynamic analysis research has been conducted [3], but this work was based on a simplified mathematical model of the suspension and does not consider the dynamic influence of the track. Other research, which is usually conducted in a single simulation environment, is lacking systematic and quantitative analysis of how the hydropneumatic parameters affect the ride safety [4].

Determining the dynamic behavior of the track and its interactions with the hydropneumatic suspension system is very difficult to achieve mathematically. This is due to the complex nature of the nonlinear multibody system. Multibody dynamics (MBD) simulation has long been recognized as an excellent method to predict the dynamic response of vehicles [5-9]. One of the key advantages of this approach is that it allows nonlinear elements such as the accumulator and the damping of the hydropneumatic suspension to be modeled readily.

The introduction of hydropneumatic suspension components that require extensive use of mathematical functions brings challenges for existing software that use the MBD 
TABLE 1: Evaluation parameters and criteria of the ride safety.

\begin{tabular}{lccc}
\hline Parameter & Symbol & Unit & Criteria \\
\hline RMS value of the track-wheel gap & $D_{\text {rms }}$ & $\mathrm{mm}$ & $<(1 / 3)$ height of the track teeth \\
RMS value of the wheel dynamic force & $F_{\mathrm{rms}}$ & $\mathrm{kN}$ & $<(1 / 3)$ static load of the road wheel \\
RMS value of the stroke of the actuation cylinder & $S_{\mathrm{rms}}$ & $\mathrm{mm}$ & $<(1 / 3)$ designed stroke length \\
RMS value of the jumping quantity of the track & $W_{\mathrm{rms}}$ & $\mathrm{mm}$ & $<(1 / 3)$ effective engage length between the track and the sprocket teeth \\
\hline
\end{tabular}

approach and may restrict its use. MBD cosimulation gives a suitable framework for coupling software tools which specialize in different fields of mechanics without sacrificing overall accuracy, particularly if based on different mathematical methods [10].

The approach adopted here integrates the MBD software (RecurDynV8R3 [11]) used for modeling complex configurations of the tracked vehicle and the road model, with LMS Imagine.Lab AMESim14.0 [12] used for the development of hydropneumatic systems. RecurDyn is a computer aided engineering tool for MBD analysis. It is capable of simulating vibrations, motions, stress, and rigid-flexible coupling analysis. Its Track (HM) module is excellent for modeling high mobility tracked vehicles. LMS Imagine.Lab AMESim is a software package used for modeling complex physical systems containing mechanical, hydraulic, electronic, thermal, and control components.

On the basis of these conditions, the detailed mechanical configurations and hydropneumatic elements can be modeled more readily using a cosimulation approach. The enormous and complicated calculations relating to the dynamic behavior of flexible objects such as tracks can be fulfilled. This leads to more accurate relationships between the parameter variations and the output variables. In this paper, the hydraulic-mechanical cosimulation on a virtual $\mathrm{G}$ road is conducted. Insights into how the hydropneumatic parameters affect the vehicle ride safety are achieved. The results can be readily used in the design, optimal control, and failure detection of a hydropneumatic suspension system.

This paper is organized as follows. A detailed description of the ride safety of tracked vehicles and the numerical model development is presented in Section 2; Section 3 shows the validation process and validity of the constructed model; Section 4 reports the cosimulation results and the analysis; finally, conclusions are presented in Section 5.

\section{Model Development}

2.1. Ride Safety and Its Evaluation Parameters. For a high mobility tracked vehicle, the suspension design and tuning should improve the ride comfort on the condition that the ride safety is guaranteed. From the point of view of surviving in the battlefield, the ride safety is generally more important than the ride comfort. The ride safety of wheeled vehicles is usually evaluated by the dynamic load of the wheel. In contrast to wheeled vehicles, the special structure of the track and its interactions with the running system brings new problems to the ride safety. The factors that affect ride safety and the evaluation parameters with their criteria are proposed as follows.
(1) Track separating from the road wheel or the sprocket: the failures of the track separating from the road wheel or the sprocket are usually caused by continuous running after the relative position of the track and the road wheel (sprocket) is skewed. The main causes may be (a) the gap between the track and the road wheel which is too large (often over the teeth height) usually caused by variations in the hydropneumatic suspension parameters, (b) the track excessive jumping caused by insufficient track tensioning force [13], and (c) large lateral forces acting on the road wheel when the vehicle turns or runs on a side slope.

By comparing the above three causes, it is identified that the first two are more critical than the third. Thus, the trackwheel gap and the quantity of jumping are taken as evaluation parameters for determining whether track separation from the road wheel or sprocket has occurred.

(2) End-stop impact of suspension: at the end-stop of the suspension the arm hits into the bumper [14]. This can cause enormous shock to the crew and may damage the arm and the hull. In a hydropneumatic suspension, the suspension stroke variation is categorized as a Gaussian random process. This means that if the RMS (root of mean square) value of the stroke of the actuation cylinder is higher than one-third of the designed stroke length, collision with the bumper is a possible event $[15,16]$.

(3) Wheel-ground adhesion ability: wheel-ground adhesion is evaluated by the relative dynamic load of the wheel, which is the ratio of the dynamic load and static load of the wheel. If the RMS of the ratio is more than $1 / 3$, the wheel load on the road will be negative and the wheel-ground adhesion deteriorates [17]. For a multiwheel tracked vehicle, although some individual wheels may lift off, the static load of the others increases and so the total ground adhesion of the vehicle will not change very much. However, the increase of dynamic load on the first or last wheel will cause the steering torque to decrease and the turning diameter to increase. This causes deterioration in how vehicle turning is controlled. Similar to wheeled vehicles, the relative dynamic load of the wheel is also an evaluation parameter for tracked vehicles.

As the values of the proposed evaluation parameters listed above belong to a Gaussian random distribution, a statistical metric is more meaningful for evaluating the ride safety. Table 1 shows the ultimate evaluation parameters and their criteria used in this paper.

2.2. Vehicle and Road Modeling. As mentioned previously, a conventional calculation method based on the simplified mathematical model (high degree of linearization of the system stiffness and damping) is not suitable for a complicated nonlinear multibody system [18]. The approach 


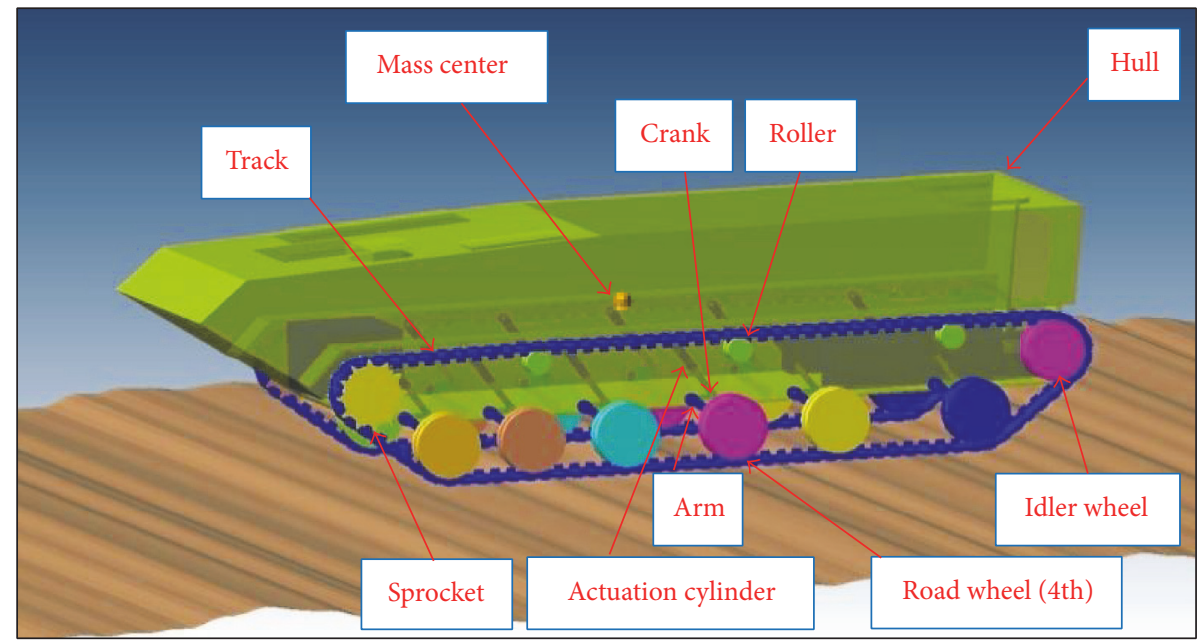

Figure 1: Vehicle dynamic model and G road model.

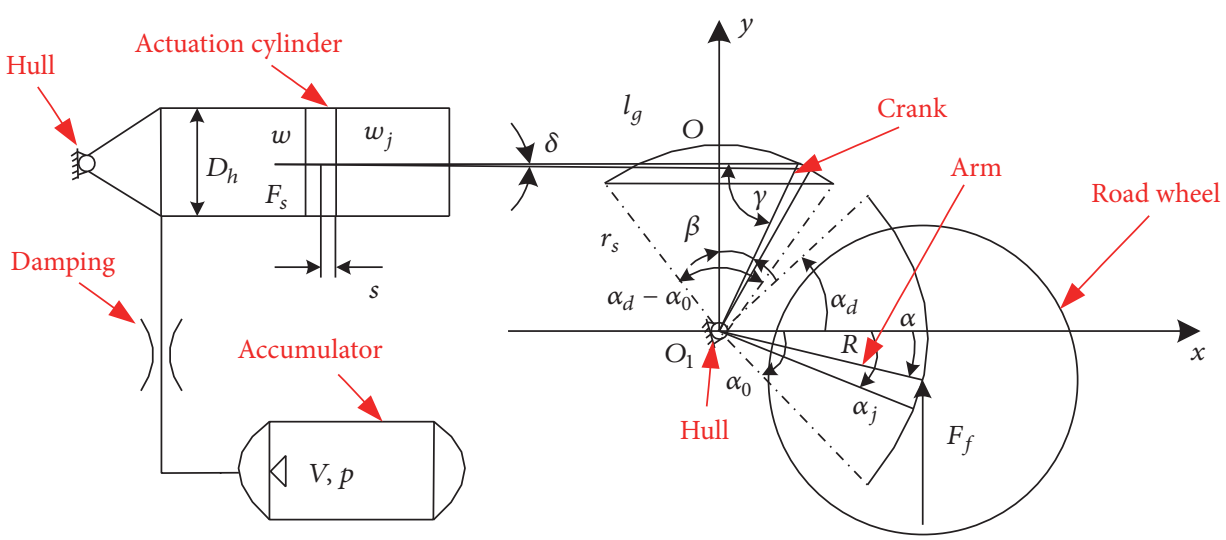

FIGURE 2: Connection sketch of hydropneumatic suspension.

cannot effectively solve the interactions between the track and ground and the track and road wheels and the effect of track tightening force on the track. In this paper, the approach of MBD cosimulation is used to establish the vehicle dynamics model and the ground model.

(1) Vehicle model: the vehicle components were first modeled using a CAD toolkit. Then, the model is exported to the RecurDyn, where the mass, joint constraints, and the motions are assigned. The model, which is shown in Figure 1, consists of the hull, the suspension system, and the track assemblies [19]. Each track assembly is composed of a sprocket, road wheels, an idler, rollers, and a track. According to the actual structure of the vehicle, the running system has 6 pairs of road wheels and arms with actuation cylinders; 3 pairs of supporting rollers; 1 pair of idlers; 1 pair of sprockets; and 101 track plates. The parameters values of these parts are in accordance with those of a real vehicle. The total mass of the structure is about 28.5 tons.

(2) Mechanical model of hydropneumatic suspension: the connection sketch of a single hydropneumatic suspension unit with the hull is shown in Figure 2. The actuation cylinder is connected to the hull by a revolution joint. The arm, which is fixed with a crank pin, is assembled in the hole of the bottom plate through a supporting bearing. The crank and the crank pin are fixed and turn simultaneously with the arm.

Based on the configuration of Figure 2, the equations of the vehicle's equivalent stiffness and damping are shown as follows:

$$
\begin{aligned}
& k=i^{2} k_{s}+F_{s} \frac{d i}{d f}, \\
& c=i^{2} c_{d},
\end{aligned}
$$

where $i$ is the suspension transmission ratio, $F_{s}$ is the gas spring force, $k_{s}$ is the gas spring stiffness, $d i / d f$ is the derivative of $i$ with the vertical displacement of the road wheel $f$, and $c_{d}$ is the damping coefficient of the hydropneumatic suspension. Their mathematical expressions are shown as follows:

$$
\begin{aligned}
i & =\frac{r_{s}}{R} \cdot \frac{\sin \gamma}{\cos \delta \cos \alpha}, \\
F_{s} & =\left(p-p_{a}\right) A_{s}, \\
k_{s} & =\frac{n\left(F_{s}+p_{a} A_{s}\right)}{w},
\end{aligned}
$$


TABLE 2: Suspension initial value of the design variables.

\begin{tabular}{|c|c|c|c|}
\hline Variable & Symbol & Unit & Value \\
\hline Length of axle arm & $R$ & $\mathrm{~m}$ & 0.40 \\
\hline Crank radius & $r_{s}$ & $\mathrm{~m}$ & 0.21 \\
\hline Road wheel diameter & $d$ & $\mathrm{~m}$ & 0.60 \\
\hline Angle of the axle arm from $x$ at the static position & $\alpha_{j}$ & deg & -14.0 \\
\hline Initial angle of the axle arm from $x$ & $\alpha_{0}$ & deg & -28.0 \\
\hline Angle of the axle arm from $x$ at the top end & $\alpha_{d}$ & $\operatorname{deg}$ & 30.0 \\
\hline Designed displacement of the road wheel & $D_{w}$ & $\mathrm{~m}$ & 0.39 \\
\hline Designed stroke of the actuation cylinder & $S$ & $\mathrm{~m}$ & 0.20 \\
\hline Section area of the actuation cylinder & $A_{s}$ & $\mathrm{~m}^{2}$ & $4.4 \times 10^{-3}$ \\
\hline Working pressure of the actuation cylinder & $p$ & $\mathrm{~Pa}$ & Variable \\
\hline Standard atmosphere pressure & $p_{a}$ & $\mathrm{~Pa}$ & $1.01 \times 10^{5}$ \\
\hline Displacement of the road wheel & $f$ & $\mathrm{~m}$ & Variable \\
\hline The $x$ axis position of the piston & $w$ & $\mathrm{~m}$ & Variable \\
\hline Velocity of the actuation cylinder & $\dot{s}$ & $\mathrm{~m} / \mathrm{s}$ & Variable \\
\hline Differential pressure of the hydraulic restrictor & $\Delta p(\dot{s})$ & $\mathrm{Pa}$ & Variable \\
\hline Angle of the axle arm from $x$ & $\alpha$ & $\operatorname{deg}$ & Variable \\
\hline Angle of the crank from $y$ & $\beta$ & deg & Variable \\
\hline The angle between the crank and the actuation cylinder & $\gamma$ & $\operatorname{deg}$ & Variable \\
\hline The gas polytrophic exponent & $n$ & - & 1.3 \\
\hline
\end{tabular}

$$
\begin{aligned}
\frac{d i}{d f}= & \left(\frac{r_{s}}{R^{2}}\right) \\
& \cdot \frac{1}{\cos ^{3} \alpha}\left[\sin \left(\frac{1}{2} \alpha_{d}+\alpha_{0}\right)-\frac{r_{s}}{l_{g}} \sin ^{2} \beta \cos \alpha\right], \\
c_{d}= & \frac{d F_{c}(\dot{s})}{d \dot{s}} .
\end{aligned}
$$

In $(6), F_{c}(\dot{s})$ is the damping force generated by the hydraulic restrictor of the suspension. It can be expressed as follows:

$$
F_{c}(\dot{s})=\Delta p(\dot{s}) A_{s}
$$

For the above expressions, the definition of the other variables and their initial values are given in Table 2 .

(3) Road model: the road model is derived based on the technique of solid modeling. A road roughness coefficient is an evaluation index which determines the road class. The following formula is used as the fitting expression of the power spectral density function of the international standard road:

$$
G_{q}(N)=G_{q}\left(N_{0}\right)\left(\frac{N}{N_{0}}\right)^{-\omega}
$$

where $N$ is the spatial frequency $\left(\mathrm{m}^{-1}\right), N_{0}$ is the reference spatial frequency $\left(0.1 \mathrm{~m}^{-1}\right), G_{q}\left(N_{0}\right)$ is the road power spectrum value at the reference spatial frequency, also called the road roughness coefficient $\left(\mathrm{m}^{2} / \mathrm{m}^{-1}=\mathrm{m}^{3}\right)$, and $\omega$ is the frequency index which is the diagonal slope in a double logarithmic coordinate axis $[20,21]$.
In this paper, $G$ class road is used to conduct the virtual simulation. The road file is first written in Matlab and introduced to the RecurDyn as shown in Figure 1.

2.3. Hydraulic Model of the Hydropneumatic Suspension. The hydraulic system of the hydropneumatic suspension and the interface module are modeled using AMESim, as shown in Figure 3. The model consists of 12 hydropneumatic suspension units, one pair of tension cylinders, and one interface module. Each unit is composed of an actuation cylinder, a damping tube, an accumulator, and one pair of relief valves. The hydraulic port of the actuation cylinder is connected with the accumulator and the mechanical port is linked with the interface module. The disturbance from the road causes the actuation cylinder to extend and retract. Thus, the oil flows into or out of the accumulator through the damping tube. The relief valves are set to be closed in order to study the effect of the damping tube. The tensioning cylinders are used for tightening the two tracks.

(1) Mathematical model of the actuation cylinder: the output force of the actuation cylinder contains the gas spring force $F_{s}$, the damping force generated by oil flow $F_{c}$, and the friction force $F_{f}[22,23]$. The total output force can be written as

$$
F=F_{s}+F_{c}+F_{f}
$$

where $F_{s}, F_{c}$ are defined in Section 2.1 and $F_{f}$ is expressed by

$$
F_{f}= \begin{cases}F_{f \text { sta }}, & \text { for } v_{M}=0, \\ F_{f \text { dyn }}, & \text { for } v_{M} \neq 0 .\end{cases}
$$




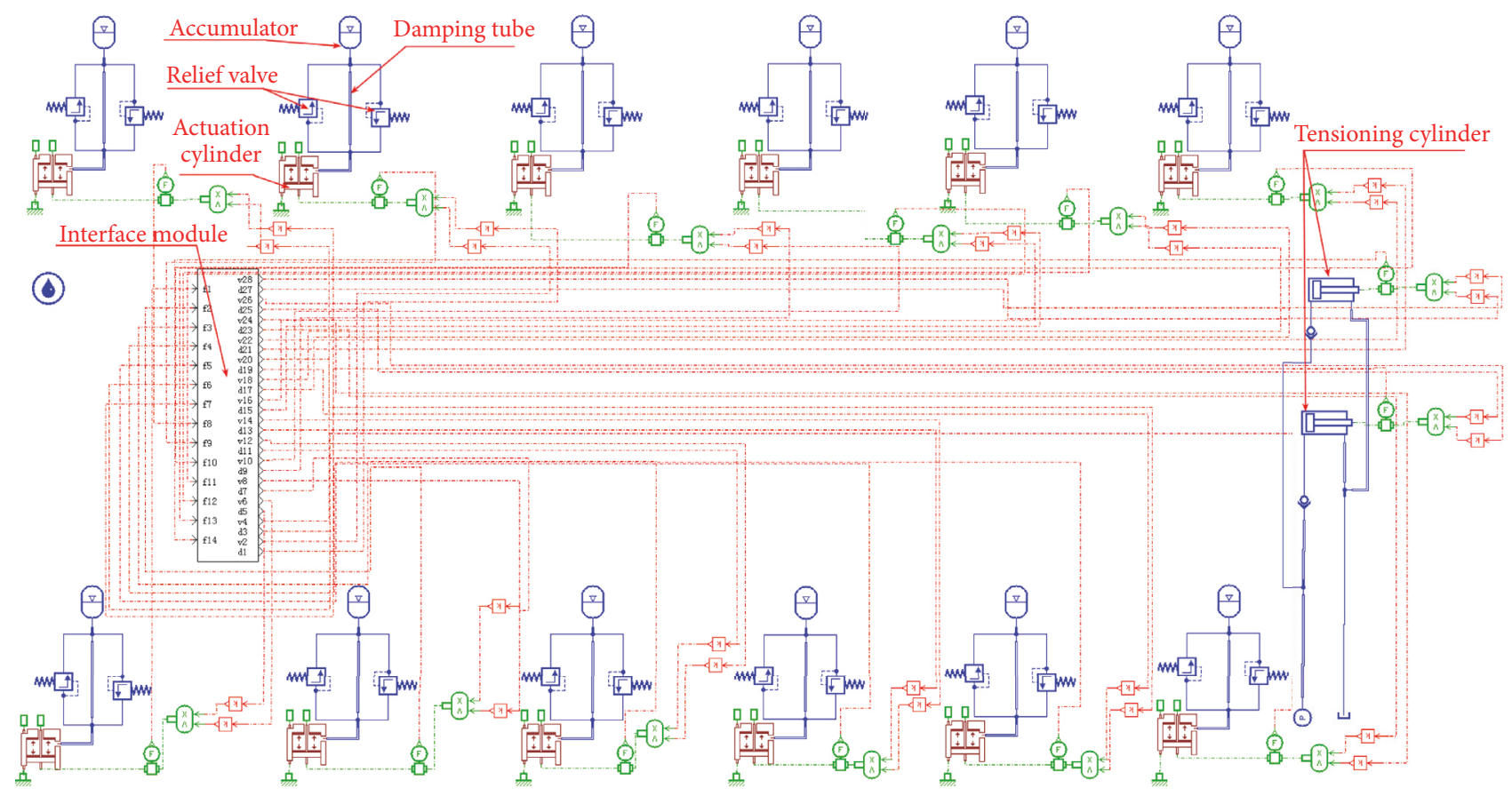

FIGURE 3: Hydraulic system model of the hydropneumatic suspension.

The static friction force and the dynamic friction force are calculated from the following, respectively.

$$
\begin{aligned}
F_{f \text { sta }}= & F_{f \text { piston }}+F_{f \text { rod }} \\
F_{f \text { dyn }}= & \left(1-\mu_{D 1} \frac{\min \left(\left|v_{M}\right|, v_{t r 1}\right)}{v_{t r 1}}\right) F_{f \text { piston }} \\
& +\left(1-\mu_{D 2} \frac{\min \left(\left|v_{M}\right|, v_{t r 2}\right)}{v_{t r 2}}\right) F_{f \text { rod }}
\end{aligned}
$$

where $F_{f \text { piston }}$ and $F_{f \text { rod }}$ are the static friction forces of the piston and the rod, $v_{M}$ is the relative velocity between the piston and the cylinder barrel, $v_{t r 1}$ and $v_{t r 2}$ are the slip velocities for fully developed dynamic friction of the piston and the rod, and $\mu_{D 1}$ and $\mu_{D 2}$ are the dynamic friction coefficients of the piston and the rod.

(2) Mathematical model of the damping tube: a long and thin damping tube is arranged between the actuation cylinder and the accumulator. According to the theory of hydraulic fluid dynamics, the pressure loss through the tube can be written as [24]

$$
\Delta p_{l}=\lambda \frac{l}{d} \frac{\rho v_{F}^{2}}{2} \operatorname{sign}\left(v_{F}\right),
$$

where $\lambda$ is the flow restriction coefficient along the tube,

$$
\lambda= \begin{cases}\frac{80}{\operatorname{Re}}, & \operatorname{Re}<2000 \\ \frac{0.3164}{\operatorname{Re}^{0.25}}, & 2000<\operatorname{Re} \leq 10^{5}\end{cases}
$$

the Reynolds number is defined as

$$
\operatorname{Re}=\frac{v_{F} d}{v}
$$

and the sign function is given as

$$
\operatorname{sign}\left(v_{F}\right)= \begin{cases}1, & v_{F}>0 ; \\ 0, & v_{F}=0 ; \\ -1, & v_{F}<0,\end{cases}
$$

where $v_{F}$ is the fluid flowing velocity, $l$ and $d$ are the length and flow diameter of the damping tube, and $\nu$ and $\rho$ are the kinematic viscosity and the density of the fluid.

(3) Mathematical model of the accumulator: the gas chamber of the accumulator is filled with pressurized nitrogen. The state changing process of the gas can be described by the following equation.

$$
p V^{n}=p_{0} V_{0}^{n}
$$

where $n$ is the gas polytrophic exponent, $V$ is the actual gas volume, $V_{0}$ is the initial gas volume, $p$ is the actual gas pressure, and $p_{0}$ is the initial gas charge pressure.

If the accumulator is loaded or unloaded rapidly, the thermodynamic process of the gas state change belongs to an adiabatic process and the value of the polytrophic exponent is $n=1.4$. Otherwise, the thermodynamic process is the isothermal process and $n=1[25,26]$. When considering its application in a real vehicle, which is under typical road disturbances, the reciprocating impact on the 
TABLE 3: Initial value of hydraulic variables.

\begin{tabular}{|c|c|c|c|}
\hline Hydraulic variables & Symbol & Unit & Value \\
\hline Initial charge pressure of the accumulator & $p_{0}$ & $\mathrm{~Pa}$ & $6.8 \times 10^{6}$ \\
\hline Volume of the accumulator & $V_{0}$ & $\mathrm{~m}^{3}$ & $0.85 \times 10^{-3}$ \\
\hline Length of the damping tube & $l$ & $\mathrm{~m}$ & 1.2 \\
\hline Flow diameter of the damping tube & $d$ & $\mathrm{~m}$ & $6 \times 10^{-3}$ \\
\hline Section area of the actuation cylinder & $A_{s}$ & $\mathrm{~m}^{2}$ & $4.4 \times 10^{-3}$ \\
\hline Initial track tensioning pressure & $p_{T}$ & $\mathrm{~Pa}$ & $6.2 \times 10^{6}$ \\
\hline Section area of the track tensioning cylinder & $A_{s}$ & $\mathrm{~m}^{2}$ & $2.0 \times 10^{-3}$ \\
\hline Density of the oil & $\rho$ & $\mathrm{kg} / \mathrm{m}^{3}$ & $0.87 \times 10^{3}$ \\
\hline Kinematic viscosity of the oil & $v$ & $\mathrm{cSt}$ & 10 \\
\hline
\end{tabular}

accumulator is usually instantaneous. However, certain heat exchange processes exist, so the state change can be considered as a process that is between adiabatic and isothermal. In this paper, the polytrophic exponent $n$ is set as 1.3 $[27,28]$.

(4) Interface module: the function of the interface module is to carry out the exchange of the simulation data between the two simulation platforms, namely, RecurDyn and AMESim. Here, each program executes its respective simulation simultaneously. At each time step $(0.001 \mathrm{sec})$, both codes update one another with new state values before advancing to the next step. Simulations begin when RecurDyn calculates the stroke and velocity of the actuation cylinder. The hydropneumatic system in AMESim calculates the force of the actuation cylinder and feed it back to the MBD vehicle model.

The interface module has 14 input ports and 28 output ports. The input ports $f 1 \sim f 12$ are designated to the actuation cylinders' output force and $f 13 \sim f 14$ denote the left and right track tensioning cylinders' output force. The output ports 1 24 represent the stroke and velocity of the actuation cylinders and 25 28 are for the track tensioning cylinders. The interface module and its connection with the suspension system are depicted in Figure 3.

\section{Model Verification}

In order to validate the model, a single hydropneumatic unit is tested using the suspension test rig shown in Figure 4. The parameters in Table 3 are used in the simulation models from (13) to (17) and are in accordance with those in the test rig. In the AMESim parameter setting mode, the values are assigned to each hydraulic model. Relative to all the forces in the actuation cylinder, the friction force is comparatively tiny. Thus, a simplification is to set the value of the fiction parameter to the system default, which is suitable for most cases. The vehicle is designated to traverse a triangle barrier at the speed of $5 \mathrm{kmph}$ as illustrated in Figure 5. Based on the above conditions, the disturbance on the road wheel is clear. On the test rig, the excitation of the vibration table is also set the same as that in the simulation.

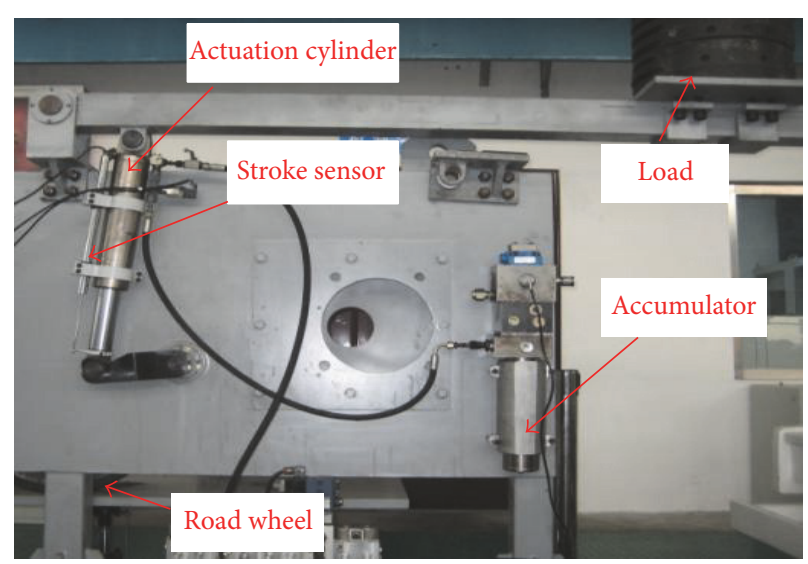

Figure 4: Test rig of the hydropneumatic suspension.

Figure 6 shows the test and simulation results of the actuation cylinder $(L 1)$ stroke. In the initial position, the track assemblies are not in contact with the ground; otherwise, the initial impact of the track on the ground would result in the simulations failing. Thus, the vehicle descends to the ground firstly and the actuation cylinders are compressed from the initial extended position to the static balance position. This is shown as an initial stroke compression in the simulation curve in Figure 6. After approximately one second, the vibrations are attenuated almost to zero and the vehicle reaches its static balance position. The change in stroke after $1.5 \mathrm{~s}$ is caused by the vehicle acceleration and the small subsequent oscillations are from the impact of road wheel with the gap between the shoe plates. The large compression in stroke after $4 \mathrm{~s}$ is the result of the road wheel bouncing when traversing the barrier. The 2 nd $\sim 6$ th road wheel passing over the barrier resulted in the signal oscillations after $5 \mathrm{~s}$. In general, the simulation results agree well with the test data.

The test and simulation results of the road wheel's (L1) acceleration are illustrated in Figure 7. In the simulation curve, except for the large acceleration caused by the barrier impact, there exist some small fluctuations induced for the same reason as discussed in Figure 6. In general, the test 


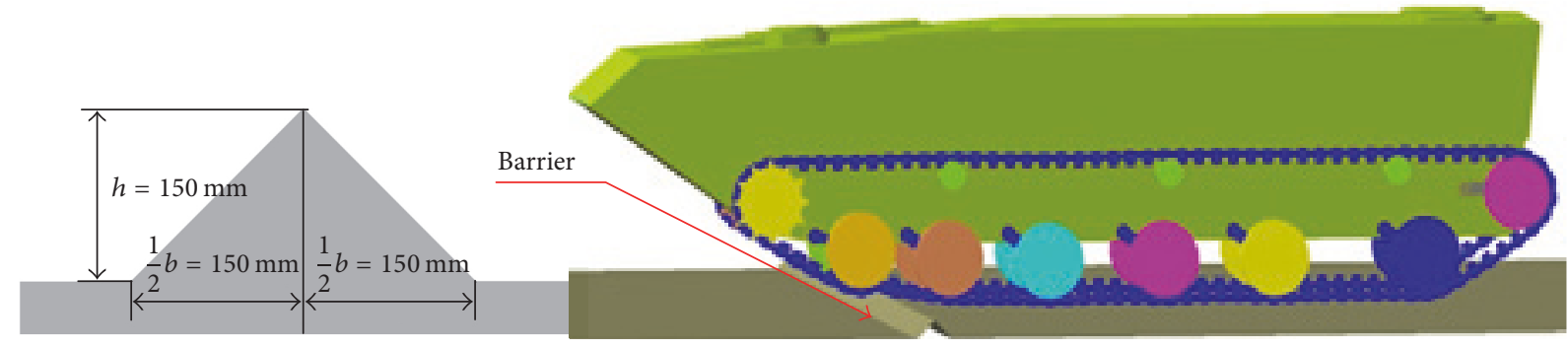

FIGURE 5: Modeling and simulation of the vehicle traversing a barrier.

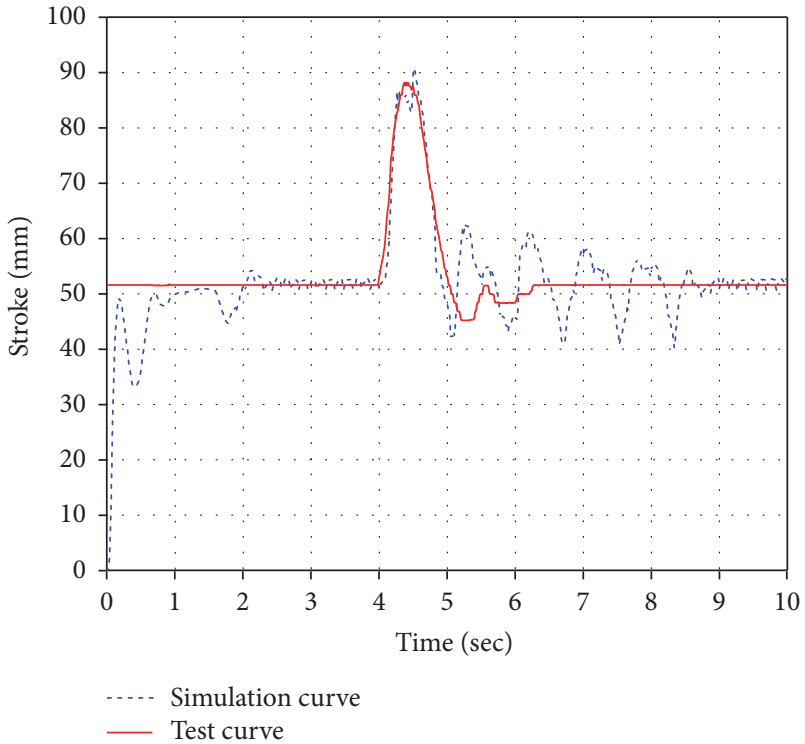

FIGURE 6: Test and simulation results of the stroke.

and simulation results matched very well and the constructed simulation model is validated.

\section{Cosimulation Analysis}

Using the modeling and simulation environment, the virtual tests on the $G$ road are conducted under different conditions such as vehicle speed, flow diameter of the damping tube; accumulator charge pressure, and track tensioning pressure. The influences of the above parameters on the vehicle ride safety are investigated.

4.1. Effect of the Damping. The damping of the hydropneumatic suspension is directly set by the flow diameter $(d)$ of the tube installed between the cylinder and the accumulator. The simulations which explore the effect of different tube diameters are conducted at different vehicle speeds. Figure 8 shows that there is always an optimal diameter which renders the RMS value of the track-wheel gap $\left(D_{\text {rms }}\right)$ to be minimum for any speeds. The optimal diameter for minimum $D_{\text {rms }}$ decreases as the speed increases. The decrease of diameter on the left side of the optimal value has a stronger influence on $D_{\text {rms }}$ than the increase of the diameter on the other side.

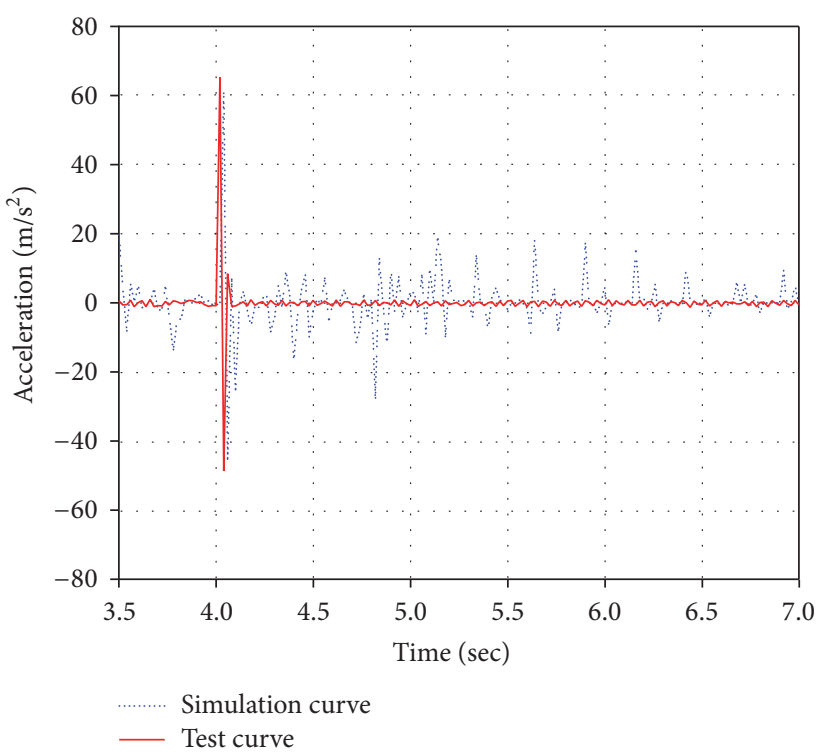

FiguRE 7: Test and simulation results of the road wheel acceleration.

Similar to Figure 8, it can be seen from Figure 9 that there always exists an optimal diameter which minimizes the RMS value of the road wheel dynamic force $\left(F_{\mathrm{rms}}\right)$, for any vehicle speeds. On the left side of the optimal value, the decrease of the diameter also has a stronger influence on $F_{\text {rms }}$. As the vehicle speed increases, the optimal diameter decreases. The higher the vehicle speed is, the stronger the effect the diameter has. Lower speed generally results in less dynamic force, but an improperly tuned diameter may cause higher dynamic force for a lower speed than that for a higher speed.

The RMS value of the stroke $\left(S_{\text {rms }}\right)$ of the actuation cylinder for different damping diameters and vehicle speeds on a G road are shown in Figure 10. It can be seen that $S_{\text {rms }}$ increases as the diameter and vehicle speed increase. For $47 \mathrm{kmph}$, as the diameter is more than $10 \mathrm{~mm}, S_{\text {rms }}$ exceeds one-third of the designed stroke length; thus an end-stop impact of the suspension will be a possible event.

4.2. Effect of the Accumulator Charge Pressure. The accumulator charge pressure determines the basic stiffness of the suspension. Through simulations and analysis of various charge pressures, the effects of the charge pressure on the RMS value of the track-wheel gap, the road wheel dynamic force, and the stroke are obtained. 


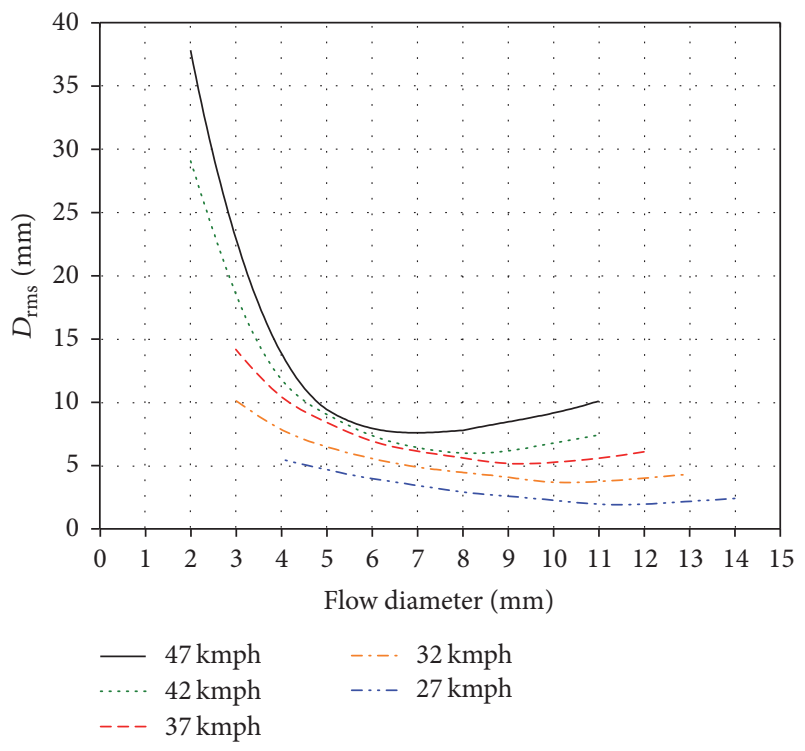

Figure 8: The RMS value of the track-wheel gap versus the flow diameter.

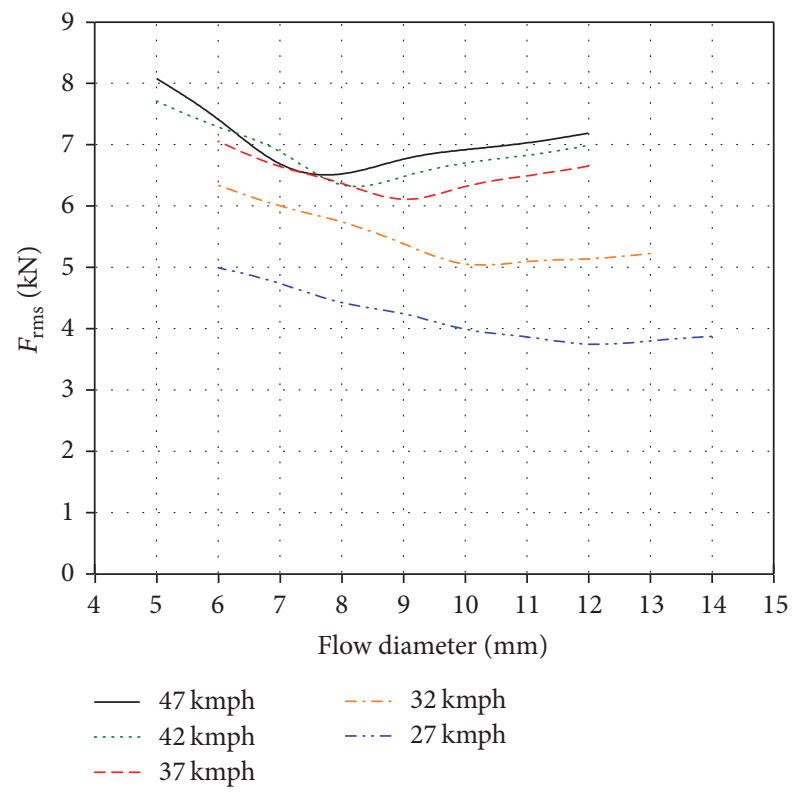

FIGURE 9: The RMS value of the road wheel dynamic force versus the flow diameter for various speeds.

Figure 11 shows how the RMS value of the wheel-track gap $\left(D_{\mathrm{rms}}\right)$ changes as the charge pressure $\left(p_{c}\right)$ changes. As the pressure decreases down to $2 \mathrm{MPa}, D_{\text {rms }}$ increases slowly. Once the pressure drops below $2 \mathrm{Mpa}, D_{\mathrm{rms}}$ increases rapidly. Thus, if $D_{\text {rms }}$ is over one-third of the grouser height, the failure of the track separating from the wheel will be possible. It is known that the height of the grouser is about $58 \mathrm{~mm}$. Therefore, if the pressure is less than about $2 \mathrm{MPa}$, the probability of occurrence of the failure increases significantly.

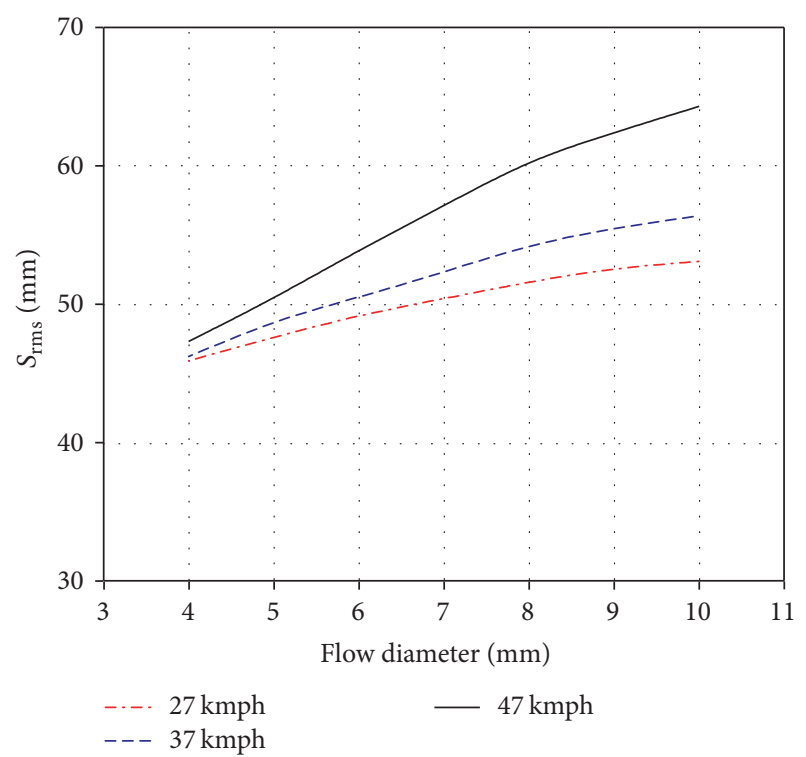

FIGURE 10: The RMS value of the stroke versus the flow diameter for various speeds.

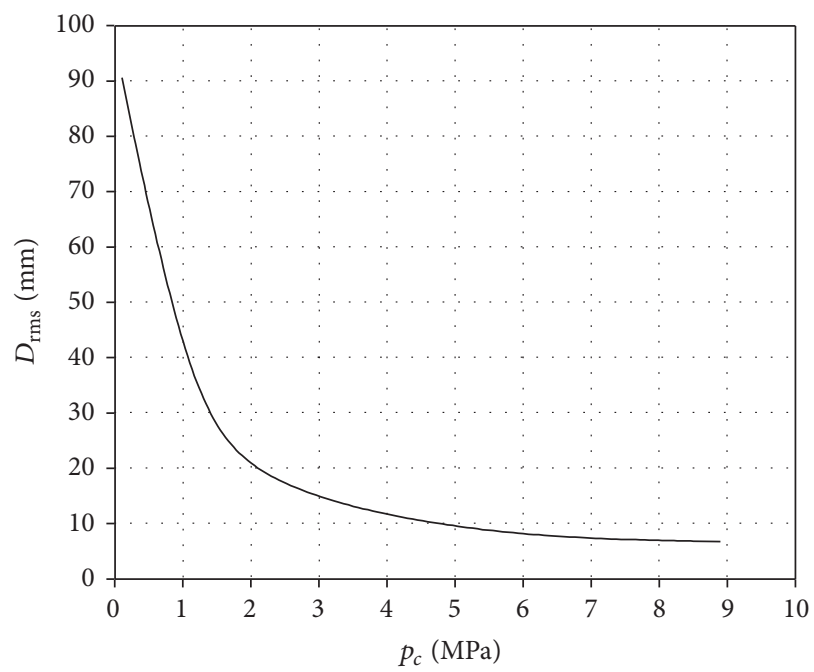

FIgURE 11: The RMS value of the track-wheel gap versus the accumulator charge pressure.

Variations of the RMS value of the road wheel dynamic force $\left(F_{\mathrm{rms}}\right)$ with charge pressure $\left(p_{c}\right)$ are illustrated in Figure 12 for various vehicle speeds. It can be seen that $F_{\text {rms }}$ increases with an increase in charge pressure at all speeds.

The RMS value of the stroke $\left(S_{\text {rms }}\right)$ for different vehicle speeds and charge pressures are given in Figure 13. Notice that when the pressure is less than about $1.5 \mathrm{MPa}, S_{\text {rms }}$ increases sharply as $p_{c}$ decreases. The designed stroke length of the actuator cylinder is $200 \mathrm{~mm}$; if $p_{c}$ drops below about $1.5 \mathrm{MPa}$ at the speed of $47 \mathrm{kmph}$, the end-stop impact of the suspension has a high probability of occurrence.

4.3. Effect of the Track Tensioning Force. The track tensioning force and its fluctuations play an important role in the ride 


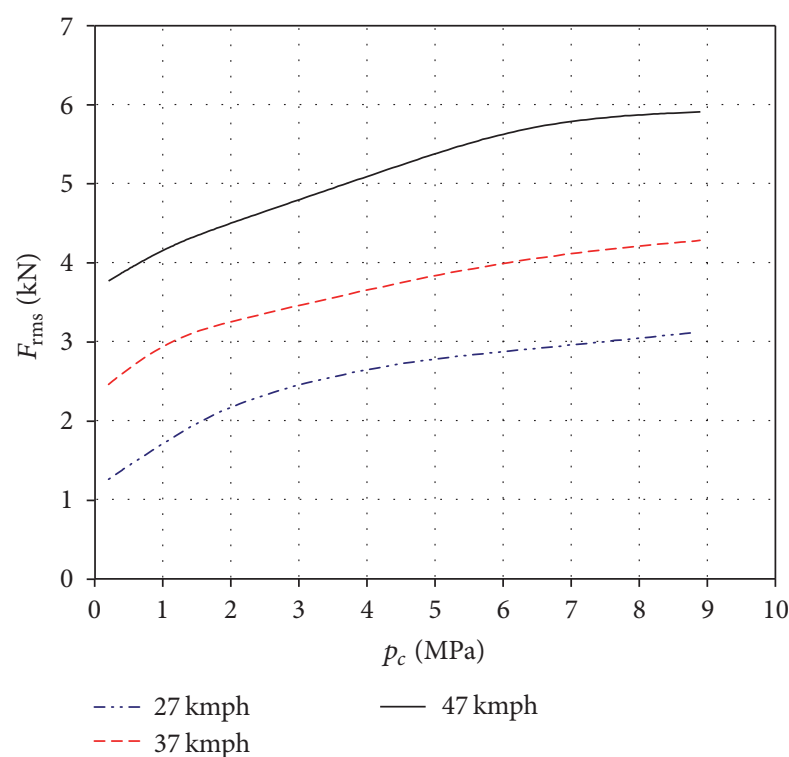

FIGURE 12: The RMS value of the road wheel dynamic force versus the accumulator charge pressure for various speeds.

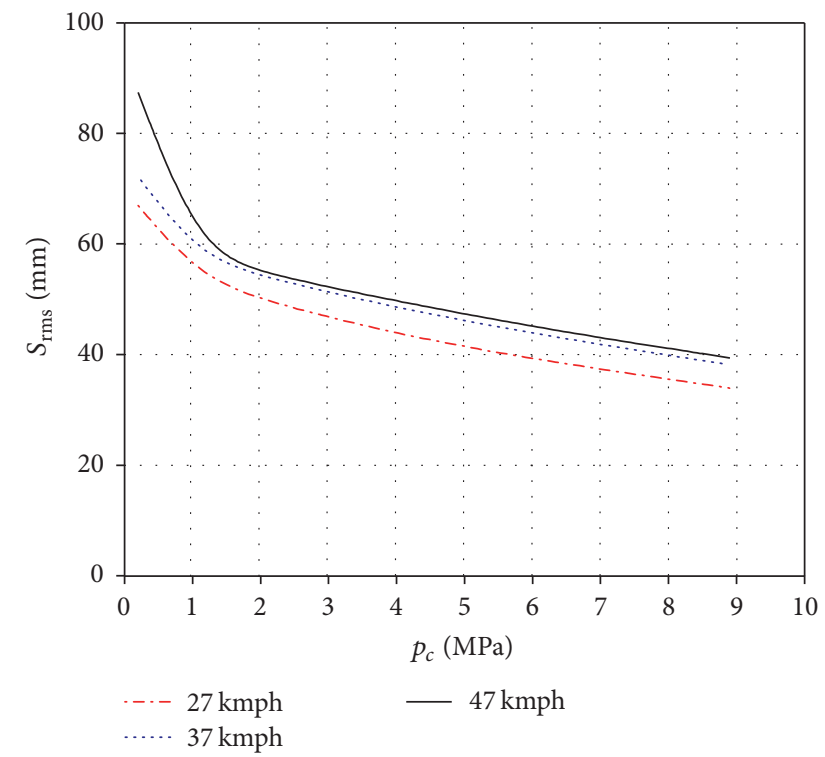

FIGURE 13: The RMS value of the stroke versus the accumulator charge pressure for various speeds.

safety of the vehicle. A decline of tensioning force will cause a rise in fluctuations and more frequent track jumping from the sprocket. Thus, the failure of the track separating from the sprocket will occur. In the hydropneumatic suspension system, a pair of hydraulic tensioning cylinders is used to adjust the track. The tensioning force is directly related to the actuating pressure $p_{T}$ and the track tensioning force fluctuations can be evaluated by its standard deviation $\left(F_{D}\right)$.

The RMS value of jumping quantity $\left(W_{\mathrm{rms}}\right)$ and the standard deviation of the tensioning force $\left(F_{D}\right)$ of the track for various pressures are given in Figure 14. Both $W_{\text {rms }}$ and $F_{D}$ increase as the pressure decreases. When the jumping

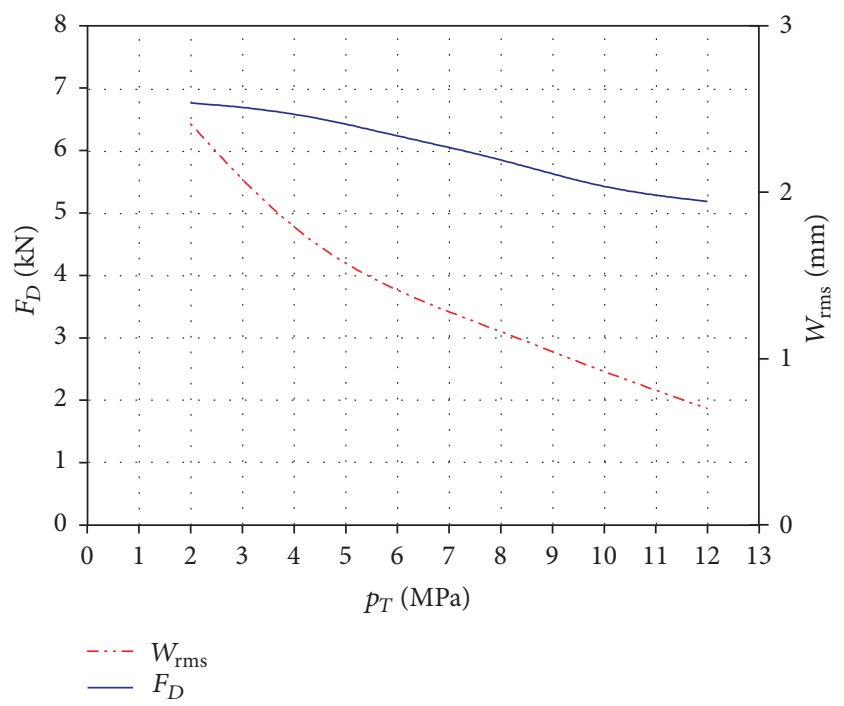

FIGURE 14: The standard deviation of track tension force and the RMS value of jumping quantity versus the actuating pressure of the track tensioning cylinder.

quantity is over the length of the effective mesh area on the sprocket teeth, the failure of the track separating from the sprocket may happen. A tighter track provides better ride safety, but, on the other hand, the force acting on the sprocket, the idler and the roller by the track will be higher. Thus, the friction force between the track and the above components increases [29]. The loss of the chassis output power on the running system will also be greater.

\section{Conclusions}

Factors which influence the ride safety of a tracked vehicle are analyzed. Systematic evaluation parameters of ride safety and their criteria are proposed. Using a cosimulation technique, the vehicle MBD model and the hydropneumatic suspension model are built and verified. Through simulations at various vehicle speeds, accumulator charge pressures, and damping diameters, the effect they have on ride safety are investigated and quantified. The key conclusions are as follows.

(1) Different optimal damping parameters exist for the minimum wheel-track gap and the wheel dynamic force at different vehicle speeds. The value of the optimal diameter decreases as the vehicle speed increases. If the diameter is not tuned well, the dynamic wheel force at a low speed may be higher than that at a high speed.

(2) As the accumulator charge pressure decreases, the RMS value of the wheel-track gap and the stroke increases but the RMS value of road wheel dynamic force decreases. For the hydropneumatic suspension studied in this paper, when the pressure drops below about $2 \mathrm{MPa}$, the probability of the end-stop impact of the suspension increases significantly. 
(3) As the actuating pressure of the track tensioning cylinder decreases, the track tensioning force decreases. An insufficient tensioning force leads to a looser track, a rise in fluctuations, and more frequent track jumping from the sprocket. Thus, the ride safety deteriorates. In order to improve the ride safety, the track tensioning force should be increased sufficiently.

\section{Conflicts of Interest}

The authors declare that there are no conflicts of interest regarding the publication of this manuscript.

\section{References}

[1] X. Dong, The dynamic analysis and simulation of tracked vehicles [Ph.D. thesis], Hunan University, Changsha, China, 2007.

[2] W. Wang, H. Huang, L. Gu et al., "Dynamic simulation on suspension vibration characteristic of tracked vehicle," Journal of Vibration and Shock, vol. 25, no. S, pp. 1016-1018, 2006.

[3] J. Y. Wong, "Dynamics of tracked vehicles," Vehicle System Dynamics, vol. 28, no. 2-3, pp. 197-219, 1997.

[4] Y. Zhu, Y. Di, and X. Guo, "Simulation of running system of tracked vehicle's performances based on ADAMS," Drive System Technique, vol. 2, no. 2, pp. 29-31, 2008.

[5] M. C. Levesley, R. Ramli, N. Stembridge, and D. A. Crolla, "Multi-body co-simulation of semi-active suspension systems," Proceedings of the Institution of Mechanical Engineers, Part K: Journal of Multi-body Dynamics, vol. 221, no. 1, pp. 99-115, 2007.

[6] M. Haiba, D. C. Barton, P. C. Brooks, and M. C. Levesley, "Using a quarter-vehicle multi-body model to estimate the service loads of a suspension arm for durability calculations," Proceedings of the Institution of Mechanical Engineers, Part K: Journal of Multi-body Dynamics, vol. 217, no. 2, pp. 121-133, 2003.

[7] M. C. Levesley, S. A. Kember, D. C. Barton, P. C. Brooks, and O. M. Querin, "Dynamic Simulation of Vehicle Suspension Systems for Durability Analysis," Materials Science Forum, vol. 440-441, pp. 103-110, 2003.

[8] Y. G. Liao and H. I. du, "Cosimulation of multi-body-based vehicle dynamics and an electric power steering control system," Proceedings of the Institution of Mechanical Engineers, Part K: Journal of Multi-body Dynamics, vol. 215, no. 3, pp. 141-151, 2001.

[9] J. Maiorana, B. P. Minaker, D. Zhang et al., "Cosimulation of active suspension," in Proceedings of the SAE 2005 World Congress \& Exhibition, pp. 363-371, 2005.

[10] S. Dietz, G. Hippmann, and G. Schupp, "Interaction of vehicles and flexible tracks by co-simulation of multibody vehicle systems and finite element track models," Vehicle System Dynamics, vol. 37, pp. 372-384, 2003.

[11] FunctionBay Inc., "RecurdynV8R3," 2014, http://www.recurdyn .com.

[12] LMS Imagine Lab, “AMESim14.0," 2015, http://www.amesim .com.

[13] Y. Zhang, L. Chen, and W. Luo, "Simulation of off wheel problem of high speed tracked vehicle based on Recurdyn," Coal Mine Machinery, vol. 35, no. 2, pp. 49-51, 2014.

[14] Y. Defu, Theory and Practice of Vehicle Suspension Shock Absorber, Weapon Industry Press, 2003.

[15] F. Ding, Dynamics of Suspension System of Tracked Armored Vehicle, National Defence Industry Press, 2004.
[16] U. Solomon and C. Padmanabhan, "Semi-active hydro-gas suspension system for a tracked vehicle," Journal of Terramechanics, vol. 48, no. 3, pp. 225-239, 2011.

[17] C. Zhou, Vehicle Suspension Design and Theory, Peking University press, 2011.

[18] Z. Tao, G. Zhiqiang, and Z. Zhili, "Simulation of off-wheel problem of high speed tracked vehicle's running system," Journal of Henan University of Science \& Technology, vol. 27, no. 6, pp. 1215, 2006.

[19] J. Guo, L. Gu, and X.-L. Li, "Effect of the damping of suspension system on the riding comfort of a tracked vehicle," Beijing Ligong Daxue Xuebao/Transaction of Beijing Institute of Technology, vol. 21, no. 4, pp. 440-444, 2001.

[20] H.-B. Jiang, J.-T. Geng, X.-L. Zhang, and T. Wang, "Study on co-simulation of vehicle suspension system employing inerter based on virtual protoype model," Zhendong yu Chongji/Journal of Vibration and Shock, vol. 29, no. 12, pp. 221-223, 2010.

[21] E. Guglielmino, T. Sireteanu, C. W. Stammers, G. Ghita, and M. Giuclea, Semi-Active Suspension Control: Improved Vehicle Ride and Road Friendliness, Springer, London, UK, 2008.

[22] W. Bauer, Hydropneumatic Suspension Systems, Springer Heidelberg, London, UK, 2010.

[23] Y.-C. Wang, X.-H. Gao, J.-H. Guo, and C.-Q. Zhang, "Research on virtual prototype of hydro-pneumatic suspension," Xitong Fangzhen Xuebao / Journal of System Simulation, vol. 18, no. 8, pp. 2183-2186, 2006.

[24] J. Wei, H. Du, X. Fang, and K. Guo, "Road-friendliness of interconnected hydro-pneumatic suspension based on ADAMS/ Simulink/AMESim," Nongye Jixie Xuebao/Transactions of the Chinese Society of Agricultural Machinery, vol. 41, no. 10, pp. 1117, 2010.

[25] G. Lin, D. Ma, and Z.-L. Zhu, "Vibration of a missilelauncher with a multi-spindled interconnected hydro-pneumatic suspension," Journal of Vibration and Shock, vol. 32, no. 12, pp. 144148, 2013.

[26] D. Zhou, G. Wang, Y. Liu, and X. Guo, "Effects of parameters of hydro-pneumatic suspension cylinder on vehicle ride comfort," Nongye Jixie Xuebao/Transactions of the Chinese Society of Agricultural Machinery, vol. 35, no. 5, pp. 25-28, 2004.

[27] $\mathrm{H}$. Wang, The vibration dynamics of the heavy vehicle with composite interconnecting oil-air suspension [Ph.D. thesis], Beijing Institute of Technology, Beijing, China, 1996.

[28] J. Liu and H. Wang, "Analysis on stiffness characteristic of hydro-pneumatic suspension system of a rubber-wheel vehicle," Mining \& Processing Equipment, vol. 37, no. 13, pp. 44-47, 2009.

[29] B. Liu, Study on dynamics of driving device of high-speed tracked vehicle [Ph.D. thesis], Beijing Institute of Technology, Beijing, China, 2015. 


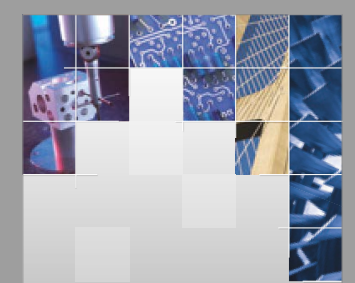

\section{Enfincering}
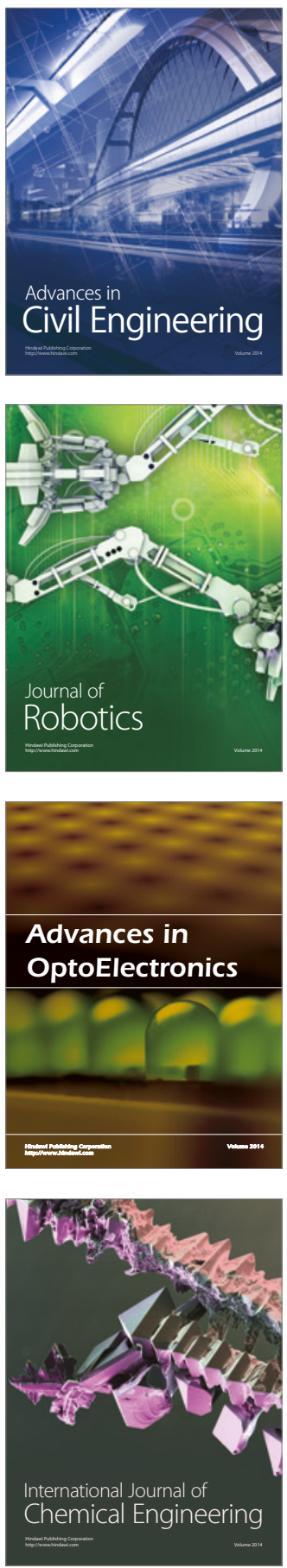

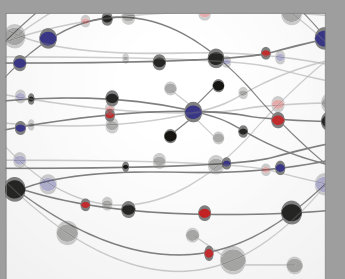

The Scientific World Journal

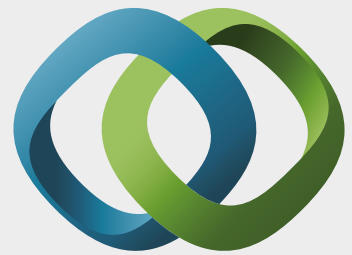

\section{Hindawi}

Submit your manuscripts at

https://www.hindawi.com
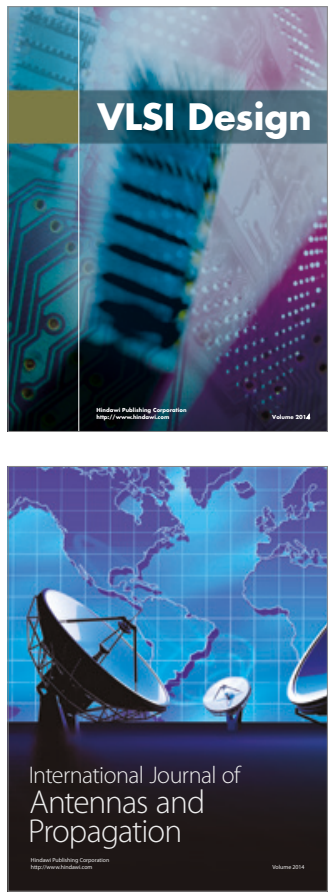

\section{Rotating}

Machinery
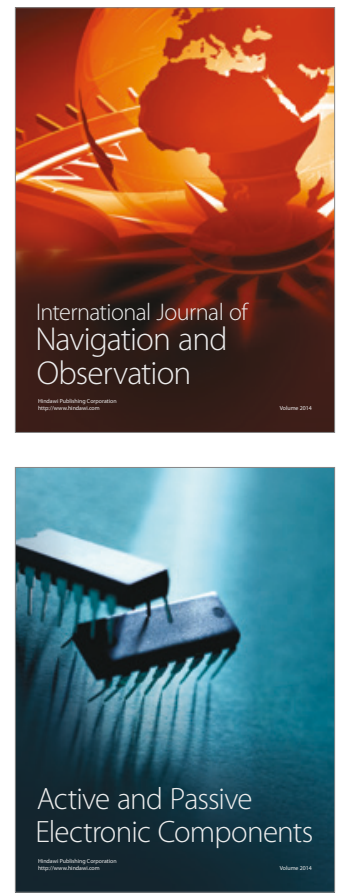
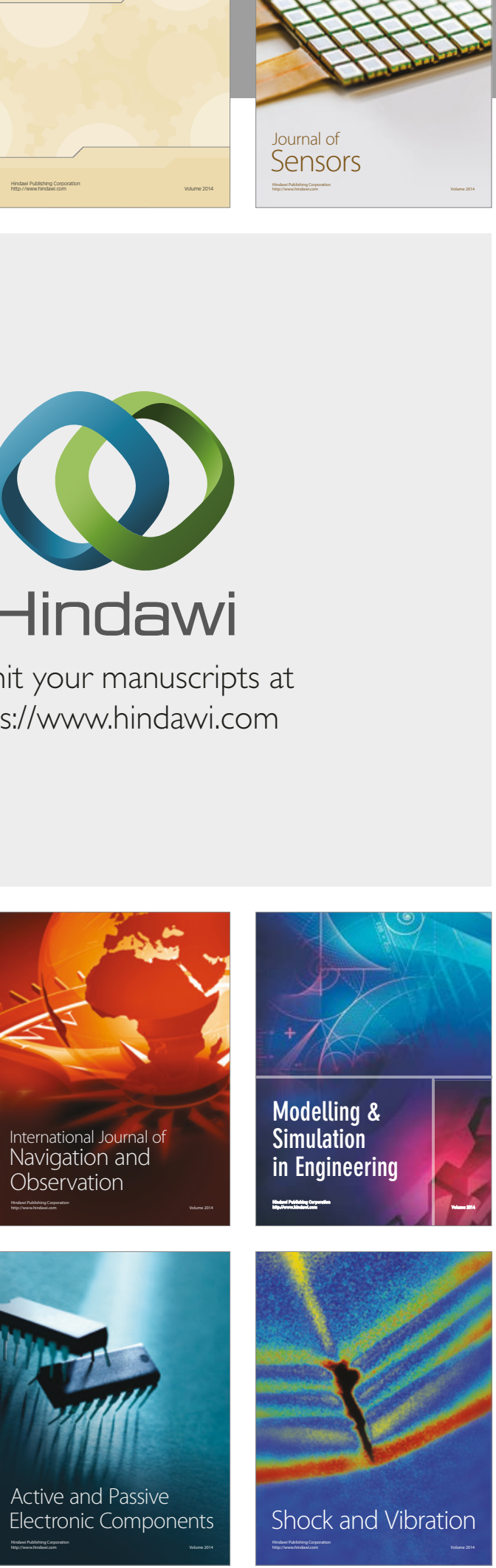
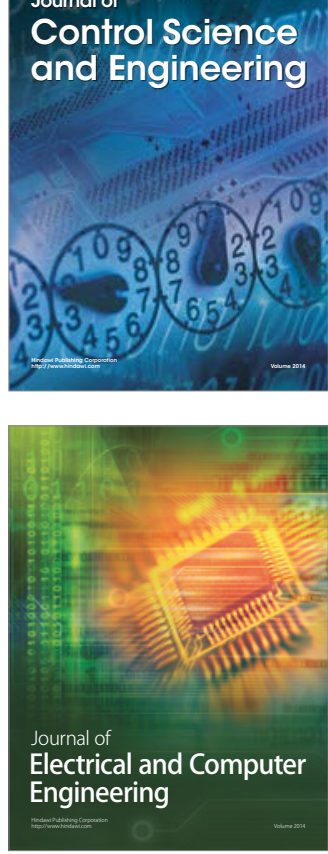

Distributed

Journal of

Control Science

and Engineering
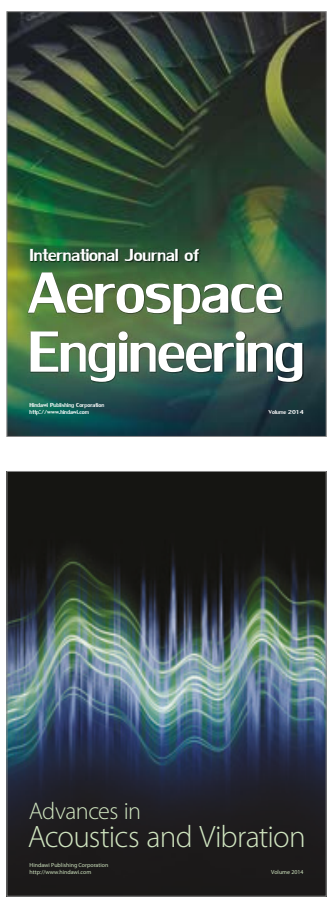

Sensor Networks 